\title{
Proceeding
}

Supplementary Issue: Autumn Conferences of Sports Science. Costa Blanca Sports Science Events, 18-19 December 2020. Alicante, Spain.

\section{High -and moderate-intensity resistance training provokes different effects on body composition, functionality, and well-being in elderly}

\author{
NICOLE B. FRITZ1,2, PEDRO GARGALLO1, ALVARO JUESAS 1 1,3, JORGE FLÁNDEZ4 ${ }^{4}$, GUILHERME E. \\ FURTADO $^{5}$, ANA M. TEIXEIRA ${ }^{5}$, JUAN CARLOS COLADO 1,5 \\ ${ }^{1}$ Research Unit in Sport and Health, University of Valencia, Valencia, Spain \\ ${ }^{2}$ Health Department, University of Los Lagos, Puerto Montt, Chile \\ ${ }^{3}$ Department of Physical Education and Sports, University of Valencia, Valencia, Spain \\ ${ }^{4}$ Institute of Education Sciences, Austral University of Chile, Ciudad de Valdivia, Chile \\ ${ }^{5}$ Research Center for Sport and Physical Activity (CIDAF), Faculty of Sport Sciences and Physical Education, \\ University of Coimbra, Portugal
}

\begin{abstract}
Purpose: To compare the short-term effects of a resistance training program with elastic bands at moderate and high intensity on the body composition, functional capacity, and well-being of overweight and obese older women. Method: 75 women $(68.7 \pm 4.7$ years) were assigned to a control group $(n=25)$ or to one of two treatment groups: (i) high intensity (G6 $=6$ repetitions, $n=25)$ and (ii) moderate intensity ( $G 15=15$ repetitions, $n=25)$. Body composition (fat and fat-free mass), functional capacity (isometric strength; 30-s-arm-curl, 30-s-chair-stand, timed up \& go test, and 6-min-walk-test [6MWT]), and well-being were evaluated before and after 8 weeks of intervention by using the 36-Item-Short-Form-Survey (SF-36). Results: 61 participants completed the study. The $\mathrm{G} 15$ group generated greater positive changes in the percentages of total and segmental fat mass $(\simeq 2.8 \%, p \leq .05)$ and better performance in the 6MWT than the other groups. The G6 group showed greater improvements in the timed up \& go and muscle strength tests than the G15 group. The G6 and G15 groups showed significant improvements in the following sections of SF-36: general health perceptions, physical functioning, mental health, and vitality. The performance of all variables worsened in the control group. Conclusions: The 8 weeks of intervention caused positive and significant changes in all study variables, although the results confirmed that this duration is insufficient to generate clear differences according to the level of exercise intensity. Nevertheless, G15 caused greater improvements in the percentage of fat mass and in aerobic resistance, whereas G6 improved the lower-limb muscle strength.
\end{abstract}

Keywords: Women; Obese; Elastic bands; Short-term training.

\section{Cite this article as:}

Fritz, N.B., Gargallo, P., Juesas, A., Flández, J., Furtado, G.E., Teixeira, A.M., \& Colado, J.C. (2021). High -and moderateintensity resistance training provokes different effects on body composition, functionality, and well-being in elderly. Journal of Human Sport and Exercise, 16(2proc), S335-S352. doi:https://doi.org/10.14198/jhse.2021.16.Proc2.18

Corresponding author. Department of Physical Education and Sports, University of Valencia, C/ Gascó Oliag 3. 46010, Valencia, Spain. https://orcid.org/0000-0002-3255-3940

E-mail: juan.colado@uv.es

Abstract submitted to: Autumn Conferences of Sports Science. Costa Blanca Sports Science Events, 18-19 December 2020. Alicante, Spain.

JOURNAL OF HUMAN SPORT \& EXERCISE ISSN 1988-5202

(c) Faculty of Education. University of Alicante

doi:10.14198/jhse.2021.16.Proc2.18 


\section{INTRODUCTION}

Obesity is an increasing problem among older people (Vincent et al., 2012). This is an important concern because aging and obesity independently contribute to reducing muscle quality and accelerating lean mass loss (Koster et al., 2011). Aging and obesity concurrently exacerbate negative physiological changes in the musculoskeletal system and provide an ideal environment for the development of sarcopenia and loss of functional capacity, which can lead to decreased quality of life and decreased longevity (Goisser et al., 2015; Tokmakidis et al., 2009; Vicent et al., 2012; Yarasheski et al., 2003).

Attention should be paid to the population of older women because of their increased life expectancy and high rates of overweight and obesity. Obesity is considered one of the five modifiable risk factors that best predict female functional decline (Sarkisian et al., 2000). In this context, physical exercise is considered the cornerstone for reducing the harmful effects of a sedentary lifestyle, including obesity, because physical exercise can undoubtedly improve the health and well-being of older adults (Goisser et al., 2015). In overweight and obese older adults, the literature recommends exercise not only for weight loss but also for health and functional capacity improvement, which occur independently of changes in body mass index (Bruce et al., 2008). Accordingly, there is a consensus in the scientific literature that resistance training can reduce the risk of cardiometabolic diseases, falls, cognitive deficiencies, osteoporosis, and muscle weakness, and even decrease the rate of premature mortality among older adults (Brochu et al., 2003; Bruce et al., 2008; Carrasco-Poyatos; Cassihas et al., 2007; Degens et al. 2009; Garber et al., 2011).

From an exclusively applied standpoint, several parameters could affect the intensity of a strength training program (e.g., pace of muscle contraction, recovery time between repetitions or between sets, time under tension, and type of overload), although load magnitude is one of the most commonly used variables for differentiating exercise intensities (Toigo \& Boutellier, 2006). According to Garber et al. (2011), different intensities directly related to load can be used in strength training: high intensity, which is defined as using loads $>80 \%$ one-repetition maximum (1RM), and moderate intensity, which is defined as using loads ranging from $60 \%$ to $70 \% 1$ RM. Usually, high intensity corresponds to $\leq 6$ maximum repetitions and moderate intensity corresponds to 8-15 maximum repetitions (Ratamess et al., 2009), which can be effectively used for submaximal effort (Davies et al., 2016). Traditionally, the progression of strength training is programmed from low or moderate to high intensity (Ratamess et al., 2009) at a frequency of two training sessions per week (Ibañez et al., 2005; Murlasits, et al., 2012). However, in recent years, and despite the risk that may result from the total load magnitude, the need for older adults to begin their high-intensity training as early as possible has been raised because it is possible for them to quickly improve their ability to gain strength. Nevertheless, whether this improvement can provide them with other benefits toward improving their functional and physiological capacities, which can positively affect their health and quality of life, remains unknown (Moors et al.,2004; Peterson et al., 2011; Raymond et al., 2013). Elastic bands have emerged as an effective, affordable, portable, and easy-to-maintain alternative material that could be used for training at different intensities to improve muscle strength (Colado et al., 2020a; Flandez et al., 2020; Gene-Morales et al., 2020; Liao et al., 2018; Martins et al., 2013; Rieping et al., 2019). Moreover, these materials make it possible to easily and effectively control the intensities applied, by combining the number of target repetitions with the width of the grip in a specific band and with the type of effort for specific purpose (Colado et al., 2010; Colado et al., 2014; Colado et al., 2018; Colado et al., 2020b). This strength training method with elastic bands has been successfully used in different types of older populations (Chupel et al., 2017; Fritz et al., 2018; Gargallo et al., 2018; Rieping et al., 2019). 
Thus, to address the aforementioned concerns, this study aimed to compare the short-term effects of a resistance training program with elastic bands at moderate and high intensity on the body composition, functional capacity, and well-being of overweight and obese older women. The study hypothesis was that any benefits in body composition and functional capacity would depend on intensity, whereas no differences in self-perceived well-being would occur between the intervention groups. Conversely, the control group (CG) was expected to show worse results in all study variables. From a practical standpoint, this study aims to clarify the expected improvements in functional capacity, body composition, and well-being according to the prescribed exercise intensity when subjecting overweight or obese older adults to a short-term training program aimed toward promoting healthy aging.

\section{METHODS}

\section{Study design}

This study was a randomized controlled trial with a blind experimental design, conducted at Municipal Senior Centers of the Valencian Community. The participants were randomly assigned to one of three study groups: (i) high-intensity resistance training with elastic bands (6 repetitions, G6 group), (ii) moderate-intensity resistance training with elastic bands (15 repetitions, G15 group), and (iii) CG (in which the participants maintained their usual lifestyle). Evaluations were performed before and after 8 weeks of intervention. The study was performed in accordance with the Declaration of Helsinki (1964, revised in 2001). The ethics committee of the University of Valencia (Spain) approved the experimental protocol (H1395923230221). The data reported in the present study are part of a global research project studying physiological and functional adaptations among older adults during resistance training programs with different devices and intensities. Some data have already been published before this project (Fritz et al., 2018). The study adhered to the CONSORT (Consolidated Standards of Reporting Trials) Statement to ensure transparent and standardized information.

\section{Participants}

Older adults of the Valencian Community (Spain), more specifically of the city of Valencia, were invited to participate through the local press, promotional posters, and personal invitations by technicians at the Municipal Senior Centers of the Valencian Community. Individuals who met the following criteria were included in the study: (i) age $\geq 60$ years, (ii) female sex, (iii) body mass index $\geq 25 \mathrm{~kg} / \mathrm{m}^{2}$, (iv) without physical exercise or participation in a training program in the previous 6 months, (v) can walk $100 \mathrm{~m}$ without using a walking stick and climb 10 steps without resting, and (vi) with physician referral. Individuals who had any of the following conditions were excluded from the study: (i) uncontrolled hypertension, (ii) degenerative joint disease or joint implants, (iii) cardiovascular and/or pulmonary disease precluding the practice of physical activity, or (iv) neurological deterioration.

\section{Sample size and randomization}

As shown in Figure 1, a total of 136 women showed interest in participating in the study. Of these, 21 were excluded because of failure to meet the inclusion criteria and 40 eventually declined to participate. One of the researchers enrolled the participants and performed blind randomization by using a permutation procedure based on a computer-generated list of random numbers, thereby forming three study groups with 25 women each. Then, the principal investigator informed the participants about the schedule of the training sessions. In addition, the evaluators were blinded to the study group of each participant at all times during the evaluations of the dependent variables before and after the intervention. Lastly, before starting the study, all potential participants were thoroughly informed about the purpose and procedures, as well as about the 
benefits, risks, and discomforts that could result from their participation. All participants signed an informed consent form and were informed of their freedom to drop out of the study at any time.

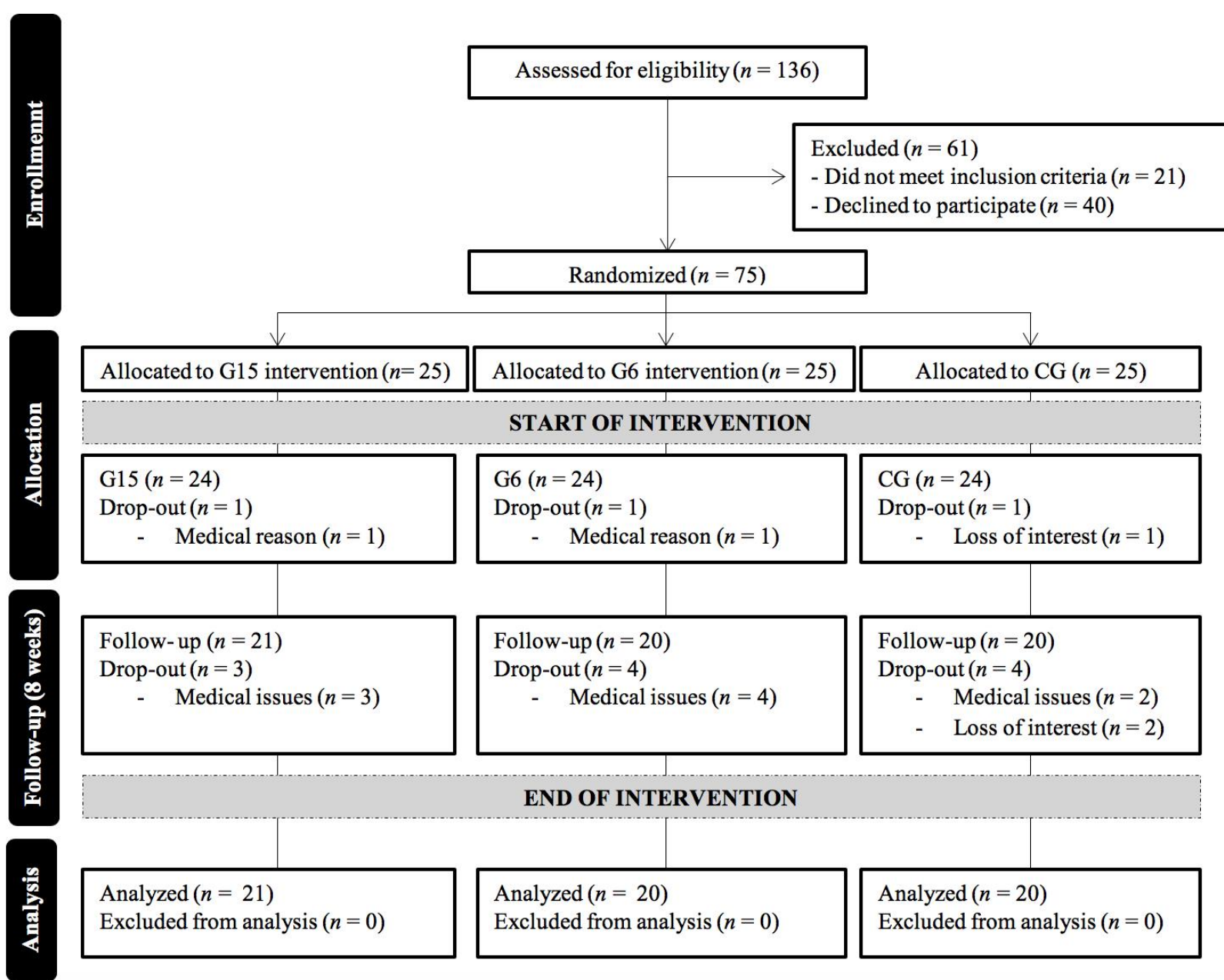

Figure 1. Flow diagram.

\section{Intervention protocol}

Intervention groups

The supervised intervention program lasted 8 weeks and included two weekly sessions of 55 min to $1 \mathrm{~h}$ performed on non-consecutive days (separated by at least $48 \mathrm{~h}$ ). The participants completed two familiarization sessions before the intervention: (i) selecting the colour and width of the grip of the elastic bands, adapting themselves to the self-perceived effort rating according to the type of experimental group to which they were assigned, and (ii) learning the correct technique of the exercises. The participants followed a periodized resistance training program using elastic bands (TheraBand $®, A k r o n, O H, U S A$ ). Each training session consisted of a 10-min general warm-up followed by a resistance training session with elastic bands (35-40 min) including three to four sets of six exercises (three for the upper limbs and three for the lower limbs), ending with a cool-down routine following the recommendations of the American College of Sports Medicine (ACSM, 2003; Garber et al., 2011). 
To ensure that the two training groups differed only in intensity, all participants followed the same training protocol (Figure 2) targeting the main muscle groups and performed in the same order. The selected exercises were the same as those previously used in the study by Fritz et al. (2018) and Gargallo et al. (2018). These exercises involved the main upper- and lower-limb muscle groups, alternately, using multiple joints, based on previous recommendations (ACSM, 2003). Intensity was controlled on the basis of the number of target repetitions and on the level of self-perceived exertion (Figure 2) assessed using the OMNIResistance Exercise Scale of perceived exertion with elastic bands, previously validated for older adults by Colado et al. (2018). A total of 6 repetitions were performed in the high-intensity group (G6) and 15 repetitions in the moderate-intensity group (G15). Following a previous study (Colado \& Triplett, 2008), the elastic bands were labelled and numbered symmetrically throughout their length to facilitate reproducibility in their grip. This method for intensity control during strength training with elastic bands has already been described and effectively used in this population profile (Fritz et al., 2018). The load was adjusted every week to maintain proper training intensities, by varying the grip width, colour, or number of the elastic bands used.

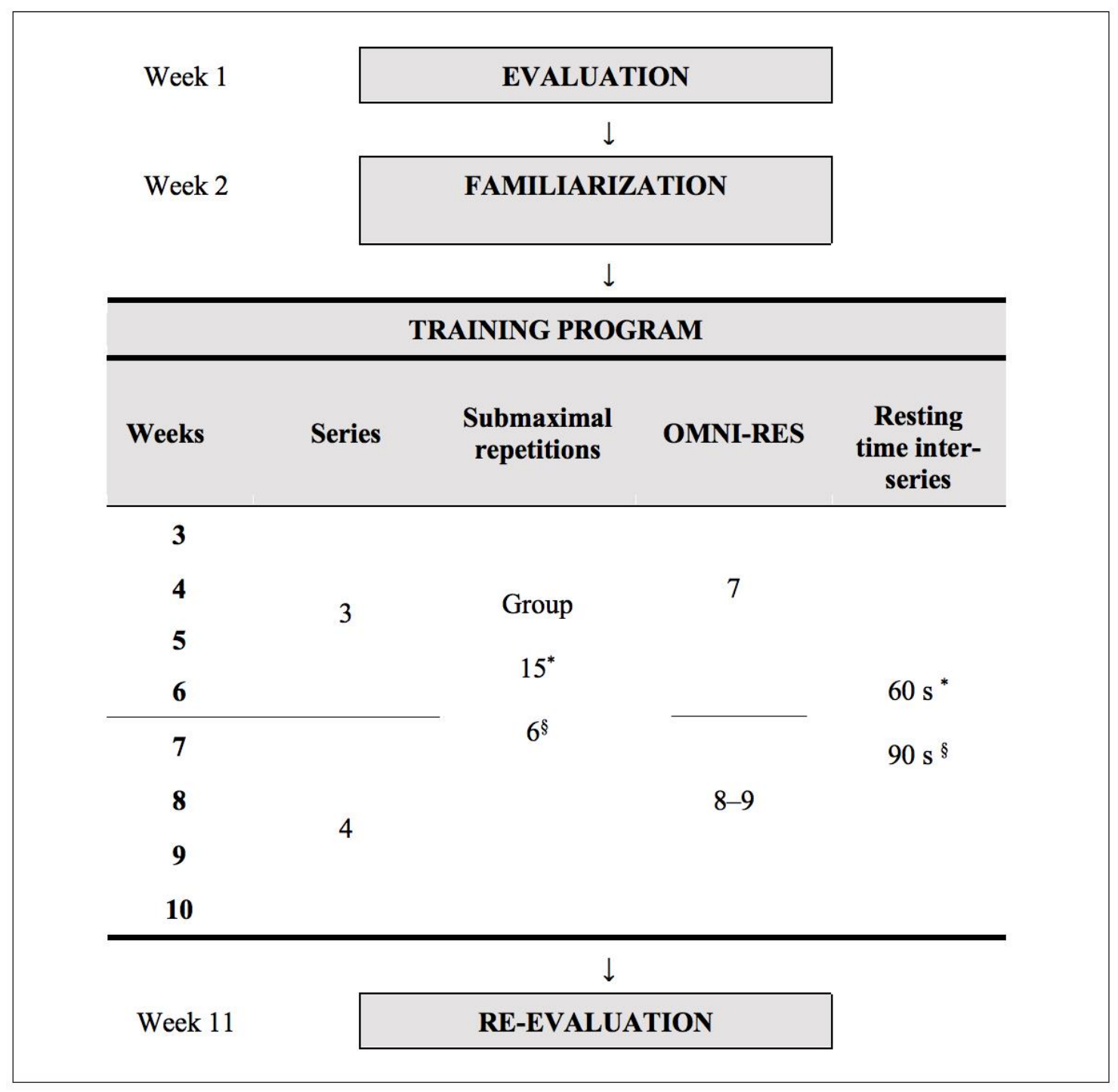

Figure 2. Diagram of the methodology of the training program. The superscripts ("or $\S)$ indicate the relationship between the number of repetitions and resting time. 
The pace of muscle contraction was controlled using a metronome to set the cadence (2s of concentric contraction and $2 \mathrm{~s}$ of eccentric contraction). In a standardized way, the participants performed rhythmic and slow movements of the extremities (120 beats/min) without elastic devices during the rest period between sets. This resistance training program was conducted under strict supervision of physiotherapists, kinesiologists, and professionals specialized in physical education and sports to guarantee safety and compliance with the intervention protocol.

\section{Control group}

The CG was instructed not to change their activities of daily living, not to perform physical activity, and to report any change in diet or the start of any physical therapy or medical treatment. To ensure strict compliance with the instructions, all these aspects were monitored weekly by asking the participants of all groups to maintain a daily diary of their activities and diet.

\section{Evaluation of the study variables}

The study variables were evaluated during the 2 weeks before and after the training program in consecutive days. Body composition was evaluated on the first day, and physical tests were performed, and a health questionnaire was administered on the second day. All measurements were standardized and performed using the same equipment by the same highly qualified staff. The following dependent variables were evaluated:

(i) Body composition. Electrical bioimpedance analysis was performed using a Tanita ${ }^{\circledR}$ body composition analyser (model BC-418MA, Tanita Corporation, Tokyo, Japan). The percentage of fat mass and the kilograms of total and segmental fat mass (fat-free muscle mass) were assessed. To ensure the accuracy of this evaluation, the instructions provided by Dixon et al. (2005) and by the manufacturer were followed. This device provides a high correlation between appendicular lean soft tissue measured with dual-energy x-ray absorptiometry and whole-body skeletal muscle mass and percentage of body fat (Pietrobelli et al., 2004).

(ii) Functional capacity. In this study, three maximum isometric strength tests were applied (upright rowing, squat, and trunk extension), following the protocol described by Colado et al. (2010), using a load cell for such purpose (Isocontrol; ATE Micro, Madrid, Spain) and the MATLAB 7.0 software (MathWorks Inc., Natick, MA, EE.UU) for analysing the received signal strength. In addition, functional capacity was evaluated using the following battery of tests proposed by Rikli and Jones (2001):

- 30-s arm curl. This test evaluates upper-limb strength. The participant must flex and extend the elbow while holding a dumbbell for $30 \mathrm{~s}$ in a sitting position on a chair. The test has a correlation coefficient of $r=.82$ with the Cybex machine arm curl performance (Osness et al., 1990).

- 30-s chair stand. This test evaluates lower-limb strength. From the sitting position, the participant has to get up from a chair completely and return to the sitting position as many times as possible for $30 \mathrm{~s}$. The test-retest reliability in contrast to $1 \mathrm{RM}$ in leg press was $r=.78$ for men and .71 for women (Burger et al., 2001).

- Timed up \& go. This test evaluates agility and dynamic balance. This test measures the time it takes for a participant to get up from a chair, turn around a cone located $3 \mathrm{~m}$ away, and return to the sitting position. This test has a correlation coefficient $r=.81$ with the Berg Balance Scale and $r=.789$ with the Barthel Index for Activities of Daily Living (Rikli \& Jones, 2001).

- 6MWT. This test evaluates aerobic endurance. The participant must walk, without running or jogging, the farthest distance in meters in $6 \mathrm{~min}$. The test has a correlation coefficient of $r=.82$ for men and $r=.71$ for women with the treadmill test (Rikli \& Jones, 2001). 
(iii) Well-being. The version of the 36-Item Short Form Survey (SF-36) questionnaire translated into Spanish by Alonso et al. (1995) was administered to measure health-related quality of life. The instrument has eight sections assessing the self-perceived physical and mental health status (General health, Physical Function, Role Physical and Bodily Pain) and mental (Mental Health, Social Function, Role Emotional and Vitality).

\section{Statistical analyses}

PASW (Predictive Analytics Software) Statistics 18.0 was applied for statistical analysis of the data. Descriptive statistics were determined after confirming the normality of the variables using the Shapiro-Wilk test and after testing for homoscedasticity using Levene's test. Repeated-measures analysis of variance was performed to assess the training effect in each group, between different intensities (between treatment groups), and in comparison, with the CG after the intervention. When finding significant differences, the Bonferroni post-hoc test was used to identify groups with such differences. To assess whether significant differences had practical applications, effect sizes (Cohen's $d$ ) and intra-group percentage changes were also calculated. The results were interpreted following standards according to which Cohen $<0.2$ is considered a trivial effect; $0.2-0.5$, a small effect; $0.5-0.8$, a moderate effect; and $>0.8$, a large effect. For all tests used, significance was set at $p \leq .05$.

The minimal clinically important difference (MCID) of each measure, determined after the intervention, were compared to assess whether intra-group changes were clinically significant. The following MCID values of measures in older adults were retrieved from the literature: 2.53 repetitions for 30-s arm curl (Bhattacharya et al., 2016), 3.3 repetitions for 30-s chair stand (Alfonso-Rosa et al., 2014), 1 s for the timed up \& go test (Alfonso-Rosa et al., 2014), $27 \mathrm{~m}$ for the 6MWT (Alfonso-Rosa et al., 2014) and 2.0 points for the SF-36 questionnaire (Angst et al., 2001).

\section{RESULTS}

\section{Participant inclusion and baseline characteristics}

A total of 75 older women agreed to participate in the study. During the 8-week training program, 9 women from the training groups (all for medical reasons) and 5 women in the CG ( 3 for loss of interest and 2 for medical reasons) dropped out. Therefore, the remaining 61 women were analysed, of whom 41 belonged to the training groups $(G 15, n=21 ; G 6, n=20)$ and 20 belonged to the CG. Figure 1 shows the flowchart of the participants' inclusion in the study. All included participants were women, considered physically inactive according to self-reported levels of participation in recreational physical or leisure activities, and overweight or obese. The attendance rate of the intervention groups (G15 and $\mathrm{G} 6$ ) was $87.6 \%$, with no reported adverse effects during the training period. The baseline characteristics are outlined in Table 1.

Table 1. Baseline characteristics. Data are presented as the mean \pm standard deviation.

\begin{tabular}{lccc} 
& G15 & G6 & CG \\
\hline Age (years) & $67.48 \pm 4.58$ & $70.55 \pm 4.34$ & $68 \pm 5.29$ \\
Body mass $(\mathrm{kg})$ & $69.59 \pm 10.52$ & $65.91 \pm 7.54$ & $63.59 \pm 10.05$ \\
Height $(\mathrm{m})$ & $1.52 \pm 0.05$ & $1.52 \pm 0.04$ & $1.54 \pm 0.05$ \\
BMI (kg/m2) & $29.66 \pm 4.53$ & $28.44 \pm 2.40$ & $26.60 \pm 4.39$ \\
Fat mass (\%) & $38.81 \pm 6.48$ & $37.97 \pm 3.94$ & $36.04 \pm 6.68$ \\
ADL & $100 \pm 0.00$ & $100 \pm 0.00$ & $100 \pm 0.00$ \\
IADL & $7.95 \pm 0.22$ & $8 \pm 0.00$ & $8 \pm 0.00$ \\
\hline G15: moderate intensity group; G6: high-intensity group; CG: control group; BMI: body mass index; ADL: activities daily living; \\
IADL: instrumental activities daily living.
\end{tabular}




\section{Body composition}

Table 2. Intervention effects on total and segmental percentage of fat mass (\%). Data are presented as the mean \pm standard deviation.

\begin{tabular}{|c|c|c|c|c|c|c|c|c|}
\hline \multirow{2}{*}{$\begin{array}{l}\text { Body } \\
\text { segment }\end{array}$} & \multirow[t]{2}{*}{ Group } & \multirow[t]{2}{*}{ Baseline } & \multirow[t]{2}{*}{ Post } & \multirow[t]{2}{*}{$\Delta \%$} & \multirow{2}{*}{$\begin{array}{c}\text { Effect } \\
\text { size }\end{array}$} & \multicolumn{2}{|c|}{$\mathrm{Cl}(95 \%)$} & \multirow{2}{*}{$\begin{array}{c}p \text {-Value } \\
\text { (time) }\end{array}$} \\
\hline & & & & & & Lower limit & Upper limit & \\
\hline Right upper & G15 & $43.94 \pm 8.02$ & $42.71 \pm 8.31$ & $-2.79 \%$ & -0.89 & -2.093 & -0.364 & .006 \\
\hline \multirow[t]{2}{*}{$\operatorname{limb}$} & G6 & $38.24 \pm 5.16$ & $37.94 \pm 4.12$ & $-0.78 \%$ & -0.06 & -1.186 & 0.586 & .501 \\
\hline & CG & $36.56 \pm 11.41$ & $36.61 \pm 11.84$ & $0.15 \%$ & +0.00 & -0.831 & 0.941 & .902 \\
\hline Left upper & G15 & $44.75 \pm 7.52$ & $43.47 \pm 7.95$ & $-2.87 \%$ & -0.17 & -2.314 & -0.258 & .015 \\
\hline \multirow[t]{2}{*}{$\operatorname{limb}$} & G6 & $39.13 \pm 5.27$ & $38.88 \pm 4.34$ & $-0.63 \%$ & -0.05 & -1.303 & 0.803 & .637 \\
\hline & CG & $37.52 \pm 11.05$ & $37.48 \pm 11.52$ & $-0.09 \%$ & -0.00 & -1.088 & 1.018 & .947 \\
\hline Right lower & G15 & $44.44 \pm 6.11$ & $43.98 \pm 6.02$ & $-1.02 \%$ & -0.08 & -0.876 & -0.038 & .033 \\
\hline \multirow{2}{*}{$\operatorname{limb}$} & G6 & $43.77 \pm 5.20$ & $43.62 \pm 4.97$ & $-0.34 \%$ & -0.03 & -0.579 & 0.281 & .490 \\
\hline & CG & $42.25 \pm 5.41$ & $42.28 \pm 5.45$ & $0.05 \%$ & +0.01 & -0.405 & 0.455 & .908 \\
\hline Left lower & G15 & $44.35 \pm 5.93$ & $43.82 \pm 5.92$ & $-1.20 \%$ & -0.09 & -0.980 & -0.087 & .020 \\
\hline \multirow[t]{2}{*}{$\operatorname{limb}$} & G6 & $43.62 \pm 5.40$ & $43.50 \pm 5.25$ & $-0.27 \%$ & -0.02 & -0.576 & 0.338 & .605 \\
\hline & CG & $42.15 \pm 5.44$ & $42.17 \pm 5.49$ & $0.04 \%$ & +0.00 & -0.437 & 0.477 & .931 \\
\hline \multirow[t]{3}{*}{ Trunk } & G15 & $37.26 \pm 6.03$ & $36.27 \pm 6.12$ & $-2.65 \%$ & -0.16 & -1.663 & -0.318 & .005 \\
\hline & G6 & $34.49 \pm 5.73$ & $34.29 \pm 5.13$ & $-0.57 \%$ & $-0,04$ & -0.889 & 0.489 & .564 \\
\hline & CG & $32.59 \pm 8.73$ & $32.46 \pm 8.76$ & $-0.39 \%$ & -0.01 & -0.819 & 0.559 & .707 \\
\hline \multirow[t]{3}{*}{ Total } & G15 & $38.81 \pm 6.48$ & $37.70 \pm 6.25$ & $-2.83 \%$ & -0.17 & -1.622 & -0.580 & .000 \\
\hline & G6 & $37.97 \pm 3.94$ & $37.71 \pm 3.64$ & $-0.68 \%$ & -0.07 & -0.794 & 0.274 & .333 \\
\hline & CG & $36.04 \pm 6.68$ & $36.22 \pm 6.68$ & $0.49 \%$ & +0.03 & -0.354 & 0.714 & .502 \\
\hline
\end{tabular}

Note. Interpretation of Cohen's effect size: $<0.2=$ trivial effect, $0.2-0.5=$ small effect, $0.5-0.8=$ moderate effect, and $>0.8=$ large effect. $\Delta \%=$ percentage difference between pre- and posttest; Cl: confidence interval; G15 = moderate intensity group; G6 = highintensity group; $C G$ = control group. Numbers in bold = significant differences between pre-post intervention.

Table 3. Intervention effects on total and segmental fat free mass $(\mathrm{kg})$. Data are presented as the mean \pm standard deviation.

\begin{tabular}{|c|c|c|c|c|c|c|c|c|}
\hline \multirow{2}{*}{$\begin{array}{l}\text { Body } \\
\text { segment }\end{array}$} & \multirow{2}{*}{ Group } & \multirow{2}{*}{ Baseline } & \multirow{2}{*}{ Post } & \multirow{2}{*}{$\Delta \%$} & \multirow{2}{*}{ Effect size } & \multicolumn{2}{|c|}{$\mathrm{Cl}(95 \%)$} & \multirow{2}{*}{$p$-Value (time) } \\
\hline & & & & & & Lower limit & Upper limit & \\
\hline \multirow{3}{*}{$\begin{array}{l}\text { Right upper } \\
\operatorname{limb}\end{array}$} & G15 & $2.00 \pm 0.28$ & $2.01 \pm 0.27$ & $0.23 \%$ & +0.04 & -0.024 & 0.033 & .737 \\
\hline & G6 & $2.09 \pm 0.33$ & $2.11 \pm 0.31$ & $1.07 \%$ & +0.06 & -0.006 & 0.051 & .126 \\
\hline & CG & $1.96 \pm 0.26$ & $1.95 \pm 0.25$ & $-0.38 \%$ & -0.04 & -0.036 & 0.021 & .607 \\
\hline \multirow{3}{*}{$\begin{array}{l}\text { Left upper } \\
\text { limb }\end{array}$} & G15 & $2.03 \pm 0.32$ & $2.04 \pm 0.32$ & $0.58 \%$ & +0.03 & -0.020 & 0.044 & .457 \\
\hline & G6 & $2.09 \pm 0.34$ & $2.11 \pm 0.31$ & $0.83 \%$ & +0.06 & -0.015 & 0.050 & .287 \\
\hline & CG & $1.94 \pm 0.25$ & $1.93 \pm 0.26$ & $-0.38 \%$ & -0.04 & -0.040 & 0.025 & .647 \\
\hline \multirow{3}{*}{$\begin{array}{l}\text { Right lower } \\
\text { limb }\end{array}$} & G15 & $6.64 \pm 0.90$ & $6.66 \pm 0.86$ & $0.39 \%$ & +0.02 & -0.036 & 0.088 & .402 \\
\hline & G6 & $6.60 \pm 0.78$ & $6.64 \pm 0.75$ & $0.60 \%$ & +0.05 & -0.024 & 0.104 & .214 \\
\hline & CG & $6.21 \pm 0.67$ & $6.22 \pm 0.68$ & $0.16 \%$ & +0.01 & -0.054 & 0.074 & .754 \\
\hline \multirow{4}{*}{$\begin{array}{l}\text { Left lower } \\
\text { limb }\end{array}$} & G15 & $6.65 \pm 0.87$ & $6.68 \pm 0.85$ & $0.39 \%$ & +0.03 & -0.033 & 0.085 & .380 \\
\hline & G6 & $6.58 \pm 0.78$ & $6.62 \pm 0.76$ & $0.68 \%$ & +0.05 & -0.016 & 0.106 & .143 \\
\hline & CG & $6.18 \pm 0.63$ & $6.19 \pm 0.63$ & $0.16 \%$ & +0.02 & -0.051 & 0.071 & .743 \\
\hline & G15 & $21.61 \pm 5.01$ & $21.68 \pm 4.94$ & $0.30 \%$ & +0.01 & -0.136 & 0.269 & .513 \\
\hline \multirow[t]{3}{*}{ Trunk } & G6 & $23.07 \pm 2.78$ & $23.23 \pm 2.92$ & $0.69 \%$ & +0.06 & -0.048 & 0.368 & .128 \\
\hline & CG & $21.84 \pm 2.72$ & $21.82 \pm 2.81$ & $-0.09 \%$ & -0.001 & -0.228 & 0.188 & .848 \\
\hline & G15 & $40.33 \pm 4.38$ & $40.50 \pm 4.56$ & $0.43 \%$ & +0.04 & -0.165 & 0.514 & .307 \\
\hline \multirow[t]{2}{*}{ Total } & G6 & $40.47 \pm 4.54$ & $40.72 \pm 4.60$ & $0.61 \%$ & +0.05 & -0.100 & 0.596 & .159 \\
\hline & CG & $38.94 \pm 3.88$ & $38.96 \pm 3.96$ & $0.05 \%$ & +0.01 & -0.326 & 0.370 & .900 \\
\hline
\end{tabular}

Note. Interpretation of Cohen's effect size: $<0.2=$ trivial effect, $0.2-0.5=$ small effect, $0.5-0.8=$ moderate effect, and $>0.8=$ large effect. $\Delta \%=$ percentage difference between pre- and posttest; Cl: confidence interval; G15 = moderate intensity group; G6 = highintensity group; $C G=$ control group. 
The changes in body composition parameters after the intervention are outlined in Tables 2 and 3. G15 was the only intervention group that showed significant post-intervention changes in the percentage of total and segmental body fat. No significant post-intervention changes in muscle mass were observed in any group, and no significant differences in any variable or body segment occurred between groups. In terms of effect size, no change had a clinically relevant effect $(d<0.2)$, except for the percentage of fat mass in the right arm in G15.

\section{Functional capacity}

Changes in isometric strength assessed using the upright rowing, squat, and trunk extension tests (Figure 3d) showed significant improvements in both intervention groups (G6 and G15) after the intervention, with significant differences from the CG in all parameters and with a large effect size on all variables $(d=$ upright rowing: $\mathrm{G} 15+1.17$ and $\mathrm{G} 6+1.46$; squat: $\mathrm{G} 15+1.34$ and $\mathrm{G} 6+1.77$; trunk extension: $\mathrm{G} 15+1.31$ and $\mathrm{G} 6$ $+1.16)$. In terms of differences between intervention groups, $\mathrm{G} 6$ significantly differed from $\mathrm{G} 15$ in isometric strength based on the squat test, and this intergroup difference had a large effect size $(d=+0.98)$.

In 30-s arm curl, 30-s chair stand, timed up \& go, and 6MWT (Figure 3a, b, and c), both G15 and G6 showed significant post-intervention improvements in all study variables, with a large effect size $(d=30$-s arm curl: G15 +1.87 and G6 +1.76; 30-s chair stand: G15 +2.43 and G6 +2.40; timed up \& go: G15 +2.12 and G6 +1.39; 6MWT: G15 +1.03 and G6 +0.68), and G15 obtained greater improvements, with no significant differences between experimental groups. Both intervention groups significantly differed from the CG in the 30-s arm curl, 30-s chair stand, and timed up \& go tests. In the 6MWT, only G15 significantly differed from the $\mathrm{CG}$.

a)

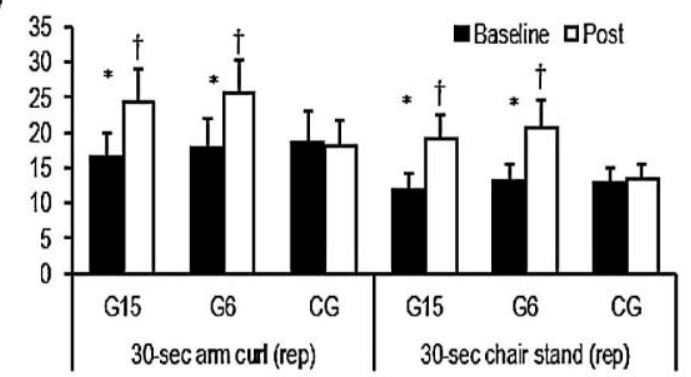

c)

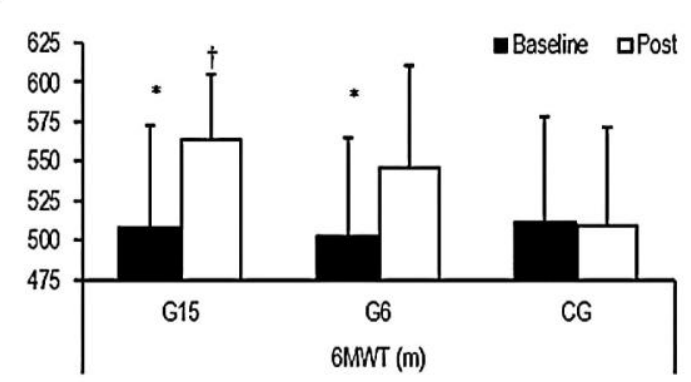

b)

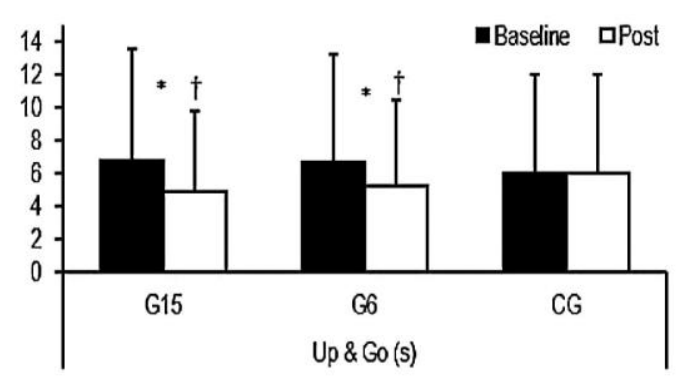

d)

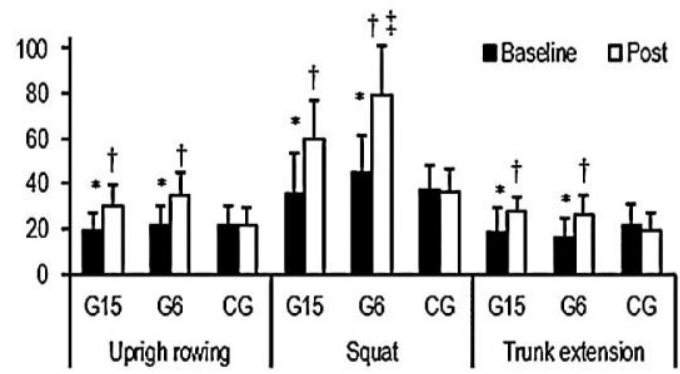

Note: Data are expressed as mean \pm standard deviation. *Significant difference from pre- to posttests $(p \leq .05)$; $†$ significant difference from CG ( $p \leq .05)$; łsignificant difference from $G 15$ ( $p \leq .05)$.

Figure 3. Intervention effects on physical performance in moderate-intensity (G15), high-intensity (G6), and control (CG) groups at baseline and after the training period. (a) 30-s-arm curl and 30-s-chair stand, (b) Timed up \& go test, (c) 6MWT, d) Isometric strength. 
Lastly, the comparison of post-intervention findings of the study groups with MCID values reported in the literature for functional capacity variables showed that the intervention brought about clinically relevant changes in both training groups and that these improvements were slightly better in G15 (MCID = 30-s arm curl: +7.77 repetitions; 30 -s chair stand +7.29 repetitions; timed up \& go: $-1.89 \mathrm{~s} ; 6 \mathrm{MWT}:+56.38 \mathrm{~m})$ than in G6 (MCID = 30-s arm curl: + 7.7 repetitions; 30 -s chair stand: 7.65 repetitions; timed up \& go: $-1.36 \mathrm{~s}$; $6 \mathrm{MWT:}$ $+43.52 \mathrm{~m})$.

\section{Well-being}

After the intervention, both training groups showed significant intra-group improvements in the following sections of SF-36: general health perceptions, physical functioning, mental health, and vitality (Figure 4); however, the effect sizes were large only in G15, except for the physical functioning section $(d=$ general health perceptions +0.97 , physical functioning +0.42 , mental health +1.18 , and vitality +0.87 ). In addition, G15 showed significant improvements in the bodily pain and social role functioning sections, albeit with small effect sizes ( $d=0.55$ and 0.47 , respectively). In terms of clinical changes, the improvements in the SF-36 sections were not clinically significant (MCDI $<2$ points).
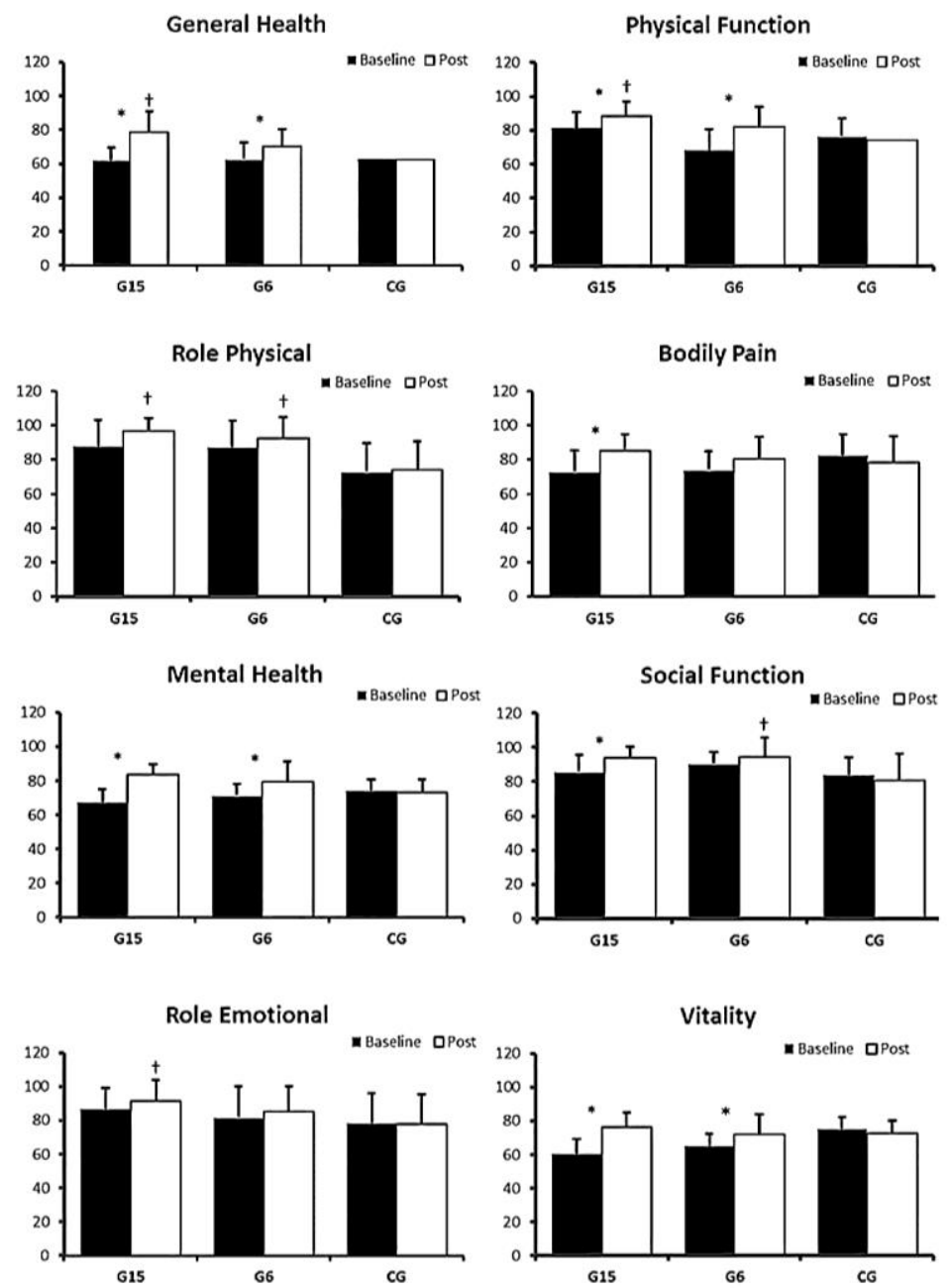

Note. *Significant difference from pre- to posttests ( $p \leq .05)$; † significant difference from CG $(p \leq .05)$.

Figure 4. Intervention effects on quality of live in moderate-intensity (G15), high-intensity (G6), and control (CG) groups at baseline and after the training period. 
Comparisons between the intervention groups and the CG showed significant improvements in the following sections of SF-36 in G15: general health perceptions, physical functioning, physical role functioning, and emotional role functioning. Conversely, $G 6$ significantly differed from the $C G$ in physical role functioning and social role functioning.

\section{DISCUSSION}

The effects of 8 weeks of resistance training with elastic bands at moderate and high intensity on the body composition, functional capacity, and well-being of overweight and obese older women were assessed in this study. On the basis of the results, G15 was the only group that showed a significant decrease in the percentage of fat mass after the interventions, whereas no significant changes in lean body mass occurred in the groups. The functional capacity variables showed the greatest statistically and clinically significant improvements, with large effect sizes, regardless of training intensity. However, G15 showed the greatest improvements in performance in the 6MWT, whereas G6 showed the greatest improvements in dynamic balance/agility and muscle strength parameters. In terms of self-perceived well-being, both training groups showed significant post-intervention improvements in the general health perceptions, physical functioning, mental health, and vitality sections. In addition, trends of significant improvement were consistently observed in all analysed variables in comparison with the CG, thus confirming the importance for this type of training program in this population profile regardless of the intensity used.

\section{Intensity and body composition}

After the intervention, significant loss of total and segmental body fat occurred only in G15. The longer time under tension in G15 in each training session, because of the higher number of repetitions, may have stimulated the increase in muscle volume, enough to promote small differences in body fat reduction from G6 (Campos et al., 2002). Moreover, G15 also involved a higher glycolysis, which maybe could have influenced fat metabolism after training (Kimber et al., 2003), and G15 also could have provoked a better hormonal stimulus for reducing fat mass (Thomas et al., 2013). This slight decrease was far from the minimum loss ( $5-10 \%$ body weight) required for older obese adults to improve their metabolic profile (Brochu et al., 2003). However, a moderate-intensity resistance training program completed alone is expected to generate losses in the percentage of fat mass of approximately $2 \%$ in only 8 weeks of training and with a low volume of weekly sessions. Nevertheless, a recent study by Liao et al. (2018) reported a loss of $2.17 \%$ total fat mass with a longer intervention time and weekly training volume than those used in our study (12 weeks, 3 sessions a week), when applying a resistance training program with elastic bands at moderate intensity ( 3 sets of 10 repetitions with a self-perceived effort of 5 out of 10) among women with sarcopenic obesity. Thus, the intervention in our study was apparently more efficient with respect to acute improvements in this parameter, most likely owing to the stronger effort and higher number of repetitions per series. Conversely, Ibañez et al. (2005) confirmed the need for a longer training time (16 weeks) to generate significant improvements in body composition, insulin sensitivity, and fasting glycemia among older adults with type 2 diabetes, as no significant effects on those parameters were observed after 8 weeks of training. Complementarily, Romero-Arenas et al. (2003) and Paoli et al. (2010) suggested that achieving stronger effects on the fat mass of older adults than those observed in our study also require reducing the rest periods between sets (i.e., to approximately $30 \mathrm{~s}$ ), similarly to circuit training, and using sessions with a larger training volume and/or higher weekly frequency (two to three times a week), in addition to dietary intervention.

Previous studies on lean body mass parameters have shown that older adults subjected to a moderateintensity training program show an increase in lean body mass similar to those who train at high intensity (Hunter et al., 2002). However, in the present study, no significant differences were found in any training 
group after the intervention, possibly owing to the short duration of the training program, similarly to effect on fat mass. In line with these findings, the studies by Martins et al. (2013) and Murlasits et al. (2012) on moderate- and high-intensity training programs, respectively, also found no significant differences after 8 weeks of training. Previous studies have shown that at least 12-16 weeks of training are necessary for counteracting sarcopenia among older adults (Degens et al., 2009) and 22 weeks are needed for reaching similar levels to those of young individuals (Candow et al., 2011). Nevertheless, studies such as that by Koster et al. (2011) highlighted that older women usually lose approximately $1 \%$ lean body mass per year. Thus, the present study has shown that the training program with elastic bands can effectively avoid this deterioration in only 8 weeks of intervention, which facilitates its applicability in different contexts and for different needs.

\section{Intensity and functional capacity}

The results of our study indicate that the 8-week protocol increased the functional capacity of overweight and obese older women regardless of training intensity. This is possibly because short-term training improves neuromuscular activity motor unit synchronization and agonist muscle activation, thereby improving the functional capacity of older adults without significant structural improvements (Murlasits et al., 2012; Straight et al., 2012), as observed in our study.

The comparison of our results with those of other studies that also used elastic bands for strength training, despite differences in the method for controlling the training intensity and with higher training intensity and weekly volume than those of our study, shows that these studies have led to less improvement in strength and dynamic balance than those achieved in our study, most likely owing to the differences in the training programs (Carrasco-Poyatos \& Reche Orenes, 2017; Liao et al., 2018; Motalebi \& Loke, 2014).

Although no significant differences were found between groups after the intervention, our study showed positive effects of the intervention in muscle strength and balance tests in G6, while highlighting improved performance in 6MWT (which is a test that inherently requires greater muscular strength) in G15. As previously reported in the literature, these differences likely result from training at intensities equal to or higher than $80 \% 1 \mathrm{RM}$, as in G6, thus primarily stimulating increases in the muscle strength of older adults (Vicent et al., 2012; Yarasheski et al., 2003). This would explain the improved performance in muscle strength tests of this population with this program duration.

In terms of improvements in dynamic balance and agility measured using the timed up \& go test, G6 apparently benefited more owing to the greater increase in leg muscle strength resulting from the applied training intensity (Raymond et al., 2013; Young \& Farrow, 2006). Conversely, the characteristics of the training in $\mathrm{G} 15$ can increase the stimulation of fatigue-resistant muscle fibres and therefore is expected to improve the performance in the 6MWT (Ades et al., 1996; Hunter et al., 2004; Locks et al., 2012). In general, G15 showed very good results in both functional tests of muscle strength and maximum strength tests, thus showing that this training program generates neuronal adaptations similar to that induced by $\mathrm{G} 6$ in the upper limbs and trunk in this short-term resistance training program. However, G15 is less effective than G6 for the lower limbs, most likely because the legs are more engaged in activities of daily living than the arms and trunk, and therefore require a higher basal intensity than that provided in G15 for improvements, although the participants were older adults with a sedentary lifestyle (Peterson \& Gordon, 2011; Tokmakidis et al., 2009). 


\section{Intensity and perception of well-being}

Muscle strength training positively affected the health perceptions of older adults, both in the physical functioning and mental health sections of the SF-36, in contrast to the control participants who perceived a worsened health status in this short period. Similar results have been reported by Cassilhas et al. (2007), who assessed the impact of 24 weeks of strength training at moderate and high intensity by using the SF-36 questionnaire. In line with our study, they showed that, regardless of the intensity used, muscle strength training equally benefitted older people. In addition, similarly to Cassilhas et al. (2007), we also observed that members of the group who trained at moderate intensity showed greater percentage changes over time in the vitality (G15: $15.61 \%$ versus G6: $10.74 \%$ ) and general health perceptions (G15: $27.53 \%$ versus G6: $12.17 \%$ ) sections of the SF-36. Thus, moderate intensity is apparently more tolerated and accepted by older adults (Kraemer et al., 2002; Morss et al., 2004). Raymond et al. (2013) confirmed these findings. They indicated that, regardless of training intensity (high, moderate, or low), exercise has the same beneficial effects on functionality, mood, and quality of life. However, intensity-dependent effects are expected when assessing depression symptoms. Therefore, this variable also needs to be analysed in future studies, considering the increasing rates of depression among older adults reported in the literature (Kok \& Reynolds, 2017).

Although the present study rigorously controlled for all factors that could have affected the findings, some biases remain, such as the loss of participants in the CG and the impossibility of making comparisons according to sex. Thus, our results may not be generalizable to all elderly populations. Future research should consider including men in the study group, to analyse and compare the behaviour of dependent variables according to sex. Dietary parameters and physical activity levels that could have affected our conclusions on changes in body composition were monitored and supervised at all times, and no change in those habits was observed in any participant during the application of the program. However, future studies using a more precise instrument for measuring body composition than that used in our study, in addition to more sophisticated techniques for monitoring daily physical activity and diet, are necessary. Moreover, mediumand long-term studies are required to assess whether the positive differences resulting from the different intensities used could be maintained after the short-term acute adaptations.

\section{CONCLUSION}

In conclusion, the present study showed that 8 weeks of training caused positive and significant changes in all study variables, although this period is not long enough to generate large differences according to intensity level. Nevertheless, G15 generated greater improvements in the percentage of fat mass and aerobic resistance than G6, whereas G6 markedly yielded significant improvements in lower-limb muscle strength. Without training, all variables of body composition, functional capacity, and well-being worsened in this age group. Therefore, on the basis of the findings of the present study, overweight and obese older women should start a training program at moderate intensity to gain positive effects on body composition, functional capacity, and well-being, and subsequently progress to a high-intensity training program for further neuromuscular improvements, especially in the lower limbs. These improvements may also lead to greater increases in dynamic balance and/ or agility. Further, this study showed that lower-limb strength is more easily improved in this population when using high-intensity training and that older women with a sedentary lifestyle perceive moderate-intensity training as more tolerable than high-intensity training. Lastly, the results also confirmed the efficacy of elastic bands as a training material for this population. 


\section{FUNDING}

This work was supported by the grant Ignacio Larramendi 2014 from the Mapfre Foundation (Code: OTR2015-140931NVES). Pedro Gargallo was supported by a predoctoral scholarship (FPU15/05634) awarded by the Spanish Ministry of Education, Culture, and Sport.

\section{ACKNOWLEDGMENTS}

The authors express sincere thanks to all the subjects for their participation and the directors of the Municipal Centers of Physical Activity for Older People for taking part in the study by opening the doors of their centres. Jesus's and Mari Paz deserve special mention for their work in the development of the department for the aging on the Council of Valencia (Spain). Finally, thanks to the University Clinic of Nutrition, physical Activity and Physiotherapy of the Lluís Alcanyís Foundation (University of Valencia, Spain) for the support in the initial stages of this study.

\section{REFERENCES}

Ades, P. A., Ballor, D. L., Ashikaga, T., Utton, J. L., \& Nair, K. S. (1996). Weight training improves walking endurance in healthy elderly persons. Annals of internal medicine, 124(6), 568-572. https://doi.org/10.7326/0003-4819-124-6-199603150-00005

Alfonso-Rosa, R. M., del Pozo-Cruz, B., del Pozo-Cruz, J., Sañudo, B., \& Rogers, M. E. (2014). TestRetest Reliability and Minimal Detectable Change Scores for Fitness Assessment in Older Adults with Type 2 Diabetes. Rehabilitation Nursing, 39(5), 260-268. https://doi.org/10.1002/rnj.111

Alonso, J., Prieto, L., \& Antó, J. M. (1995). The Spanish version of the SF-36 Health Survey (SF-36 Health Questionnaire): an instrument for the measurement of clinical outcomes. Med Clin (Barc), 104(20), 771-776.

American College of Sports Medicine. (2013). ACSM's Exercise for Older Adults, Philadelphia: Lippincott Williams \& Wilkins.

Angst, F., Aeschlimann, A., \& Stucki, G. (2001). Smallest detectable and minimal clinically important differences of rehabilitation intervention with their implications for required sample sizes using WOMAC and SF-36 quality of life measurement instruments in patients with osteoarthritis of the lower extremities. Arthritis Care \& Research: Official Journal of the American College of Rheumatology, 45(4), 384-391. https://doi.org/10.1002/1529-0131(200108)45:4<384::AIDART352>3.0.CO;2-0

Bhattacharya, P., Deka, K., \& Roy, A. (2016). Assessment of inter-rater variability of the Senior Fitness Test in the geriatric population: A community-based study. International Journal of Biomedical and Advance Research, 7(5), 208-212. https://doi.org/10.7439/ijbar.v7i5.3249

Brochu, M., Tchernof, A., Turner, A. N., Ades, P. A., \& Poehlman, E. T. (2003). Is there a threshold of visceral fat loss that improves the metabolic profile in obese postmenopausal women? Metabolism, 52(5), 599-604. https://doi.org/10.1053/meta.2003.50095

Bruce, B., Fries, J. F., \& Hubert, H. (2008). Regular vigorous physical activity and disability development in healthy overweight and normal-weight seniors: a 13-year study. American Journal of Public Health, 98(7), 1294-1299. https://doi.org/10.2105/AJPH.2007.119909

Burger, H., \& Marincek, C. (2001). Functional testing of elderly subjects after lower limb amputation. Prosthetics and orthotics international, 25(2), 102-107. https://doi.org/10.1080/03093640108726582 Campos, G. E., Luecke, T. J., Wendeln, H. K., Toma, K., Hagerman, F. C., Murray, T. F., ... \& Staron, R. S. (2002). Muscular adaptations in response to three different resistance-training regimens: 
specificity of repetition maximum training zones. European journal of applied physiology, 88(1-2), 5060. https://doi.org/10.1007/s00421-002-0681-6

Candow, D. G., Chilibeck, P. D., Abeysekara, S., \& Zello, G. A. (2011). Short-term heavy resistance training eliminates age-related deficits in muscle mass and strength in healthy older males. The Journal of Strength \& Conditioning Research, 25(2), 326-333. https://doi.org/10.1519/JSC.0b013e3181bf43c8

Carrasco-Poyato, M., \& Reche-Orenes, D. (2018). Effects of an integrated physical training program in old women functional condition. Cultura_Ciencia_Deporte, 37 (13), 31-38. https://doi.org/10.12800/ccd.v13i37.1036

Cassilhas, R. C., Viana, V. A., Grassmann, V., Santos, R. T., Santos, R. F., Tufik, S. E. R. G. I. O., \& Mello, M. T. (2007). The impact of resistance exercise on the cognitive function of the elderly. Medicine \& Science in Sports \& Exercise, 39(8), 1401-1407. https://doi.org/10.1249/mss.0b013e318060111f

Chupel, M. U., Direito, F., Furtado, G. E., Minuzzi, L. G., Pedrosa, F. M., Colado, J. C., ... \& Teixeira, A. M. (2017). Strength training decreases inflammation and increases cognition and physical fitness in older women with cognitive impairment. Frontiers in physiology, 8, 377. https://doi.org/10.3389/fphys.2017.00377

Colado, J.C., Furtado, G.E., Teixeira, A.M., Flandez, J., \& Naclerio, F. (2020b). Concurrent and construct validation of a new scale for rating perceived exertion during elastic resistance training in the elderly. Journal of sports science and medicine, 19(1), 175-186.

Colado, J. C., García-Massó, X., Pellicer Catalán, M., Alakhdar, Y., Benavent, J., \& Cabeza Ruiz, R. (2010). A comparison of elastic tubing and isotop resistance exercises. International journal of sports medicine, 31(11), 810-817. https://doi.org/10.1055/s-0030-1262808

Colado, J. C., Garcia-Masso, X., Triplett, N. T., Calatayud, J., Flandez, J., Behm, D., \& Rogers, M. E. (2014). Construct and concurrent validation of a new resistance intensity scale for exercise with thera-band $\AA$ elastic bands. Journal of sports science and medicine, 13(4), 758.

Colado, J. C., Mena, R., Calatayud, J., Gargallo, P., Flández, J., \& Page, P. (2020a). Effects of strength training with variable elastic resistance across the lifespan: a systematic review. Cultura, Ciencia y Deporte, 15(44), 147-164. https://doi.org/10.12800/ccd.v15i44.1458

Colado, J. C., Pedrosa, F. M., Juesas, A., Gargallo, P., Carrasco, J. J., Flandez, J., Chupel M.U \& Naclerio, F. (2018). Concurrent validation of the OMNI-Resistance Exercise Scale of perceived exertion with elastic bands in the elderly. Experimental gerontology, 103, 11-16. https://doi.org/10.1016/i.exger.2017.12.009

Colado, J. C., \& Triplett, N. T. (2008). Effects of a short-term resistance program using elastic bands versus weight machines for sedentary middle-aged women. The Journal of Strength \& Conditioning Research, 22(5), 1441-1448. https://doi.org/10.1519/JSC.0b013e31817ae67a

Davies, T., Orr, R., Halaki, M., \& Hackett, D. (2016). Effect of training leading to repetition failure on muscular strength: a systematic review and meta-analysis. Sports medicine, 46(4), 487-502. https://doi.org/10.1007/s40279-015-0451-3

Degens, H., Erskine, R., y Morse, C. (2009). Disproportionate changes in skeletal muscle strength and size with resistance training and ageing. Journal of Musculoskeletal and Neuronal Interactions, 9(3), 123-129.

Dixon, C. B., Deitrick, R. W., Pierce, J. R., Cutrufello, P. T., \& Drapeau, L. L. (2005). Evaluation of the BOD POD and leg-to-leg bioelectrical impedance analysis for estimating percent body fat in National Collegiate Athletic Association Division III collegiate wrestlers. The Journal of Strength \& Conditioning Research, 19(1), 85-91. https://doi.org/10.1519/14053.1 
Flandez, J., Gene-Morales, J., Modena, N., Martín, F., Colado, J.C., \& Gargallo, P. (2020). Effects of power resistance training program with elastic bands on body composition, muscle strength and physical function in older women. Journal of Human Sport and Exercise, 15(4proc), S1322-S1337. https://doi.org/10.14198/ihse.2020.15.Proc4.30

Fritz, N. B., Juesas, Á., Gargallo, P., Calatayud, J., Fernández-Garrido, J., Rogers, M. E., \& Colado, J. C. (2018). Positive effects of a short-term intense elastic resistance training program on body composition and physical functioning in overweight older women. Biological research for nursing, 20(3), 321-334. https://doi.org/10.1177/1099800418757676

Garber, C. E., Blissmer, B., Deschenes, M. R., Franklin, B. A., Lamonte, M. J., Lee, I. M., ... \& Swain, D. P. (2011). Quantity and quality of exercise for developing and maintaining cardiorespiratory, musculoskeletal, and neuromotor fitness in apparently healthy adults: guidance for prescribing exercise. Medicine \& Science in Sports \& Exercise, 3(7), 1334-1359. https://doi.org/10.1249/MSS.0b013e318213fefb

Gargallo, P., Colado, J. C., Juesas, A., Hernando-Espinilla, A., Estañ-Capell, N., Monzó-Beltran, L., ... \& Sáez, G. T. (2018). The Effect of Moderate-Versus High-Intensity Resistance Training on Systemic Redox State and DNA Damage in Healthy Older Women. Biological research for nursing, 20(2), 205217. https://doi.org/10.1177/1099800417753877

Gene-Morales, J., Gené-Sampedro, A., Salvador, R., \& Colado, J. C. (2020). Adding the load just above sticking point using elastic bands optimizes squat performance, perceived effort rate, and cardiovascular responses. Journal of sports science and medicine, 19(4), 735-744.

Goisser, S., Kemmler, W., Porzel, S., Volkert, D., Sieber, C. C., Bollheimer, L. C., \& Freiberger, E. (2015). Sarcopenic obesity and complex interventions with nutrition and exercise in community-dwelling older persons-a narrative review. Clinical interventions in aging, 10, 1267. https://doi.org/10.2147/CIA.S82454

Hunter, G. R., Bryan, D. R., Wetzstein, C. J., Zuckerman, P. A., \& Bamman, M. M. (2002). Resistance training and intra-abdominal adipose tissue in older men and women. Medicine \& Science in Sports \& Exercise, 34(6), 1023-1028. https://doi.org/10.1097/00005768-200206000-00019

Ibañez, J., Izquierdo, M., Argüelles, I., Forga, L., Larrión, J., García-Unciti, M.,...Gorostiaga, E. (2005). Twice-weekly progressive resistance training decreases abdominal fat and improves insulin sensitivity in older men with type 2 diabetes. Diabetes Care, 28(3), 662-667. https://doi.org/10.2337/diacare.28.3.662

Kimber, N. E., Heigenhauser, G. J., Spriet, L. L., \& Dyck, D. J. (2003). Skeletal muscle fat and carbohydrate metabolism during recovery from glycogen-depleting exercise in humans. The Journal of physiology, 548(Pt 3): 919-927. https://doi.org/10.1113/jphysiol.2002.031179

Kok, R. M., \& Reynolds, C. F. (2017). Management of depression in older adults: a review. JAMA, 317(20), 2114-2122. https://doi.org/10.1001/jama.2017.5706

Koster, A., Ding, J., Stenholm, S., Caserotti, P., Houston, D. K., Nicklas, B. J., ... \& Schwartz, A. V. (2011). Does the amount of fat mass predict age-related loss of lean mass, muscle strength, and muscle quality in older adults? Journals of Gerontology Series A: Biomedical Sciences and Medical Sciences, 66(8), 888-895. https://doi.org/10.1093/gerona/glr070

Kraemer, W.J., Adams, K., Cafarelli, E., Dudley, G.A., Dooly, C., Feigenbaum, M.S., Fleck, S.J., Franklin, B., Fry, A.C., Hoffman, J.R., Newton, R.U., Potteiger, J., Stone, M.H., Ratamess, N.A., TriplettMcBride, T.; American College of Sports Medicine (2002). American College of Sports Medicine position stand. Progression models in resistance training for healthy adults. Medicine and science in sports and exercise, 34 (2), 364-380. https://doi.org/10.1097/00005768-200202000-00027

Liao, C. D., Tsauo, J. Y., Huang, S. W., Ku, J. W., Hsiao, D. J., \& Liou, T. H. (2018). Effects of elastic band exercise on lean mass and physical capacity in older women with sarcopenic obesity: A 
randomized controlled trial. Scientific Reports, 8(1), 2317. https://doi.org/10.1038/s41598-01820677-7

Locks, R. R., Costa, T. C., Koppe, S., Yamaguti, A. M., Garcia, M. C., \& Gomes, A. R. (2012). Effects of strength and flexibility training on functional performance of healthy older people. Brazilian Journal of Physical Therapy, 16(3), 184-190. https://doi.org/10.1590/S1413-35552012000300003

Martins, W. R., de Oliveira, R. J., Carvalho, R. S., de Oliveira, V., da Silva, V. Z. y Silva, M. S. (2013). Elastic resistance training to increase muscle strength in elderly: A systematic review with metaanalysis. Archives of Gerontology and Geriatrics, 57(1), 8-15. https://doi.org/10.1016/..archger.2013.03.002

Morss, G. M., Jordan, A. N., Skinner, J. S., Dunn, A. L., Church, T. S., Earnest, C. P., ... \& Blair, S. N. (2004). Dose-response to exercise in women aged 45-75 yr (DREW): design and rationale. Medicine \& Science in Sports \& Exercise, 36(2), 336-344. https://doi.org/10.1249/01.MSS.0000113738.06267.E5

Motalebi, S. A., \& Loke, S. C. (2014). Efficacy of progressive resistance tube training in community dwelling older adults: a pilot study. International Journal of Gerontology, 8(4), 213-218. https://doi.org/10.1016/i.ijge.2013.12.007

Murlasits, Z., Reed, J., y Wells, K. (2012). Effect of resistance training frequency on physiological adaptations in older adults. Journal of Exercise Science \& Fitness, 10 (1), 28-32. https://doi.org/10.1016/j.jesf.2012.04.006

Osness WH, Adrian M, Hoeger W, Rabb D, Wiswell R. Functional fitness assessment for adults over 60 years: A field Based Assessment. Reston: AAHPERD; 1990. p. 1-24. 5.

Paoli, A., Pacelli, F., Bargossi, A. M., Marcolin, G., Guzzinati, S., Neri, M., ... \& Palma, A. (2010). Effects of three distinct protocols of fitness training on body composition, strength and blood lactate. Journal of sport medicine and physical fitness, 50(1), 43-51.

Peterson, M. D., \& Gordon, P. M. (2011). Resistance exercise for the aging adult: clinical implications and prescription guidelines. The American journal of medicine, 124(3), 194-198. https://doi.org/10.1016/i.amimed.2010.08.020

Pietrobelli, A., Rubiano, F., St-Onge, M. P., \& Heymsfield, S. B. (2004). New bioimpedance analysis system: improved phenotyping with whole-body analysis. European journal of clinical nutrition, 58(11), 1479-1484. https://doi.org/10.1038/si.ejcn.1601993

Ratamess, N.A., Alvar, B.A., Evetoch, T.K., Hous, T.J., Kibler, W.B., Kraemer, W.J., Triplett, N.T. (2009). Progression Models in Resistance Training for Healthy Adults. Medicine \& Science in Sports \& Exercise. 41(3), 687-708. https://doi.org/10.1249/MSS.0b013e3181915670

Raymond, M.J., Bramley-Tzerefos, R.E., Jeffs, K.J., Winter, A., y Holland, A.E. (2013). Systematic review of high-intensity progressive resistance strength training of the lower limb compared with other intensities of strength training in older adults. Archives of Physical Medicine and Rehabilitation, 94(8), 1458-1472. https://doi.org/10.1016/i.apmr.2013.02.022

Rieping, T., Furtado, G. E., Letieri, R. V., Chupel, M. U., Colado, J. C., Hogervorst, E., ... \& Ferreira, J. P. (2019). Effects of Different Chair-Based Exercises on Salivary Biomarkers and Functional Autonomy in Institutionalized Older Women. Research quarterly for exercise and sport, 90(11), 1-10. https://doi.org/10.1080/02701367.2018.1563272

Rikli R, Jones J. (2001). Senior Fitness Test Manual. 2nd ed. United States: Human Kinetics.

Romero-Arenas, S., Blazevich, A. J., Martínez-Pascual, M., Pérez-Gómez, J., Luque, A. J., LópezRomán, F. J., \& Alcaraz, P. E. (2013). Effects of high-resistance circuit training in an elderly population. Experimental gerontology, 48(3), 334-340. https://doi.org/10.1016/i.exger.2013.01.007

Sarkisian, C.A., Liu, H., Gutierrez, P.R., Seeley, D.G., Cummings, S.R, Mangione, C.M. (2000). Modifiable risk factors predict functional decline among older women: a prospectively validated 
clinical prediction tool. The Study of Osteoporotic Fractures Research Group. Journal of the American Geriatrics Society, 48(2), 170-178. https://doi.org/10.1111/j.1532-5415.2000.tb03908.x

Straight, C. R., Dorfman, L. R., Cottell, K. E., Krol, J. M., Lofgren, I. E., \& Delmonico, M. J. (2012). Effects of resistance training and dietary changes on physical function and body composition in overweight and obese older adults. Journal of Physical Activity and Health, 9(6), 875-883. https://doi.org/10.1123/jpah.9.6.875

Thomas, G. A., Kraemer, W. J., Comstock, B. A., Dunn-Lewis, C., Maresh, C. M., \& Volek, J. Obesity, Growth Hormone and Exercise. Sports medicine, 43(9), 839-849. https://doi.org/10.1007/s40279013-0064-7

Tokmakidis, S. P., Kalapotharakos, V. I., Smilios, I., \& Parlavantzas, A. (2009). Effects of detraining on muscle strength and mass after high or moderate intensity of resistance training in older adults. Clinical physiology and functional imaging, 29(4), 316-319. https://doi.org/10.1111/j.1475$\underline{097 X .2009 .00866 . X}$

Toigo, M., \& Boutellier, U. (2006). New fundamental resistance exercise determinants of molecular and cellular muscle adaptations. European journal of applied physiology, 97(6), 643-663. https://doi.org/10.1007/s00421-006-0238-1

Vincent, H. K., Raiser, S. N., \& Vincent, K. R. (2012). The aging musculoskeletal system and obesityrelated considerations with exercise. Ageing research reviews, 11(3), 361-373. https://doi.org/10.1016/j.arr.2012.03.002

Yarasheski, K. E. (2003). Exercise, aging, and muscle protein metabolism. The Journals of Gerontology Series A: Biological Sciences and Medical Sciences, 58(10), 918-922. https://doi.org/10.1093/gerona/58.10.m918

Young, W., \& Farrow, D. (2006). A review of agility: Practical applications for strength and conditioning. Strength and conditioning journal, 28(5), 38-39. https://doi.org/10.1519/00126548-200610000-00006

\section{(9) $\odot \Theta \Theta$}

This work is licensed under a Attribution-NonCommercial-NoDerivatives 4.0 International (CC BY-NC-ND 4.0). 